\title{
Built-up CFS column with lacings and battens
}

\author{
Ivan Baláž ${ }^{1}$, Yvonna Koleková ${ }^{2}$, and Lýdia Moroczováa ${ }^{2 *}$ \\ ${ }^{1}$ Emeritus Professor of the Slovak University of Technology in Bratislava, Slovakia \\ ${ }^{2}$ Department of Structural Mechanics, Faculty of Civil Engineering, STU in Bratislava, Slovakia
}

\begin{abstract}
The built-up columns are generally used in industrial buildings, either as posts for cladding when their buckling length is very long, or as columns supporting a crane girder. The built-up columns are composed usually of two parallel chords interconnected by lacings or battens. In the paper the special type of built-up column will be analysed from Llentab Company. It consists from four parallel chords with cold-formed C cross-sections which are interconnected by lacing in one plane and by battens in four perpendicular planes. Such types of columns are especially convenient for the relatively high light steel halls. Analysis of the behaviour of such column will be performed: a) on the model with smeared equivalent bending and shear stiffness's using analytical solution, b) on the discrete model using FEM and commercial program ANSYS. The theory of the second order taking into account the initial imperfections and the shear deformations will be employed.
\end{abstract}

\section{Introduction and input data}

The paper deals with a special type of built-up cold-formed steel (CFS) column with a combination of battens and lacings and compares the analytical solution with the numerical one. In the paper are processed only the results of internal forces in individual chords. CFS cross-sections from Llentab Company are used. The built-up CFS column is composed of four chords of CFS cross-section elements C-8B. In the $x z$-plane, the chords are connected by lacings of CFS cross-section element C-OB in one plane and in the $x y$-plane chords are connected by battens $(200 \times 200 \times 4 \mathrm{~mm})$ in four planes. The column is loaded by axial force $N_{E d}=1000 \mathrm{kN}$, bending moment $M_{E d, y}=90 \mathrm{kNm}$ and horizontal force $H_{E d, z}=41.52 \mathrm{kN}$. The boundary conditions are: (i) in the $x z$-plane of the built-up column (perpendicular to the $y$-axis) the bottom member end is fixed and the upper end is free; (ii) in the $x y$-plane (perpendicular to the $z$-axis) is the built-up pinned-ended column. A detailed description of the geometry and designation is given in Figure 1.

\footnotetext{
* Corresponding author: Lydia.moroczova@stuba.sk
} 


\section{Analytical solution}

The used procedure is based on the Eurocodes EN 1993-1-1 [1] and EN 1999-1-1 [2], which is in $[1,2]$ limited to very simple cases. The authors showed in [3-9] continuously how the procedure $[1,2]$ may be generalised for the following built-up members: columns with various boundary conditions, with two different kinds of imperfections, under any type of loading and made of steel and aluminium alloy. These cases cannot be calculated according to simplified procedure $[1,2]$. The correctness of the results in [3 - 9] were verified by comparing the results of two independent calculations done by (i) analytical one (own program in MATHCAD) and (ii) commercial computer program (IQ 100). Comparisons showed excellent agreements. Users of the procedure may find in [3-9] also detailed distributions of internal forces and part of large parametric study. The papers [3 - 9] enable their readers to understand first the procedure on simpler cases, which is used here for extremely complex case: the two-chords single laced column with four parallel battened planes. The column cross-section consists from four $\mathrm{C}$-sections made of cold formed steel. Lacing is made from C-profiles too. The rather small values of external loading was prescribed by Swedish company, who wanted to compare results with their results in the most loaded section. In the paper therefore there are no distributions of internal forces and the values of displacements at the end of free column end, because they are very small.

\subsection{Imperfections}

The following imperfections were taken into account: (i) In the $x z$-plane is the initial sway imperfection determined according to the clause 5.3.2(3)a) in EN 1993-1-1 [1] or the clause 5.3.2(3)a) in EN 1999-1-1 [2]:

$$
\phi=\phi_{0} \alpha_{h} \alpha_{m}=\frac{1}{200} 0.6961 .0=3.48210^{-3}
$$

where $\alpha_{h}, \alpha_{m}$ and $m$ are defined in 5.3.2(3)a) [1,2]:

$$
\frac{2}{3} \leq \alpha_{h}=\frac{2}{\sqrt{L}}=0.696 \leq 1 ; \quad \alpha_{m}=\sqrt{0.5\left(1+\frac{1}{m}\right)}=1 ; \quad m=1
$$

The effects of initial sway imperfection may be replaced by systems of equivalent horizontal force introduced for each column. The total design value of the horizontal force at the top of the column after the replacement of the initial imperfections by the equivalent horizontal force:

$$
H_{E d, z, \phi}=H_{E d, z}+\phi N_{E d}=45 \mathrm{kN}
$$

(ii) In the plane $x y$-plane, the bow imperfection with amplitude $e_{o}$ shall be determined according to clause 6.4 .1 of EN 1999-1-1:

$$
e_{o}=\frac{L}{500}=0.0165 \mathrm{~m}
$$

\subsection{The material and cross-sectional properties}

The cross-sectional properties of the C-8B:

$$
A_{c h}=2.9910^{-3} \mathrm{~m}^{2} ; \quad I_{c h . z}=8.0910^{-6} \mathrm{~m}^{4} ; \quad I_{c h . y}=1.4310^{-5} \mathrm{~m}^{4}
$$


The cross-section properties of the diagonal C-OB:

$$
A_{d}=8.06510^{-4} \mathrm{~m}^{2}
$$

The material properties:

$$
E=210 \mathrm{GPa} ; f_{y b}=500 \mathrm{MPa} ; f_{u}=550 \mathrm{MPa}
$$

The cross-section C-8B: $h=170 \mathrm{~mm} ; \mathrm{b}=138 \mathrm{~mm} ; \mathrm{c}=45 \mathrm{~mm} ; \mathrm{t}=6 \mathrm{~mm} ; \mathrm{r}=5 \mathrm{~mm}$
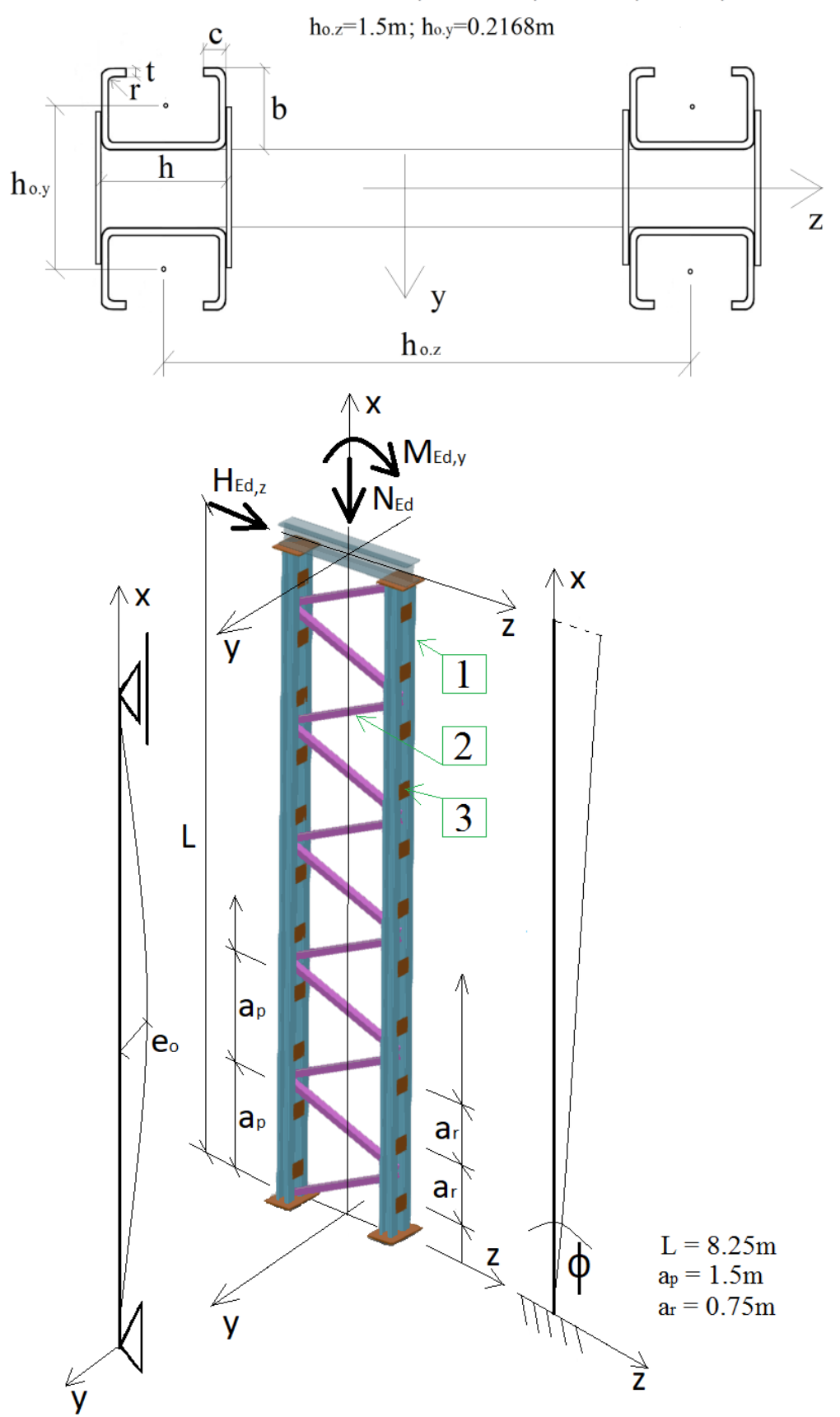

Fig. 1. Geometry of CFS-built-up column (1 - C-8B; 2 - C-OB; 3 - battens 200x200x4mm). 


\subsection{The discrete structure replaced by a continuum}

The discrete structure meets the requirement for regular spacing of lacings and battens along the length of the column and can be therefore replaced by a continuum with the shear stiffness $S_{v}$ and the effective bending stiffness $E I_{\text {eff. }}$. The effective second moments of area to the respective axes are:

$$
\begin{aligned}
& I_{e f f, z}=4\left[\mu_{z} I_{c h, z}+A_{c h}\left(\frac{h_{0, y}}{2}\right)^{2}\right]=1.72910^{-4} \mathrm{~m}^{4} ; \quad \mu_{z}=1 \\
& I_{e f f, y}=4\left[\mu_{y} I_{c h, y}+A_{c h}\left(\frac{h_{0, z}}{2}\right)^{2}\right]=6.72710^{-3} \mathrm{~m}^{4} ; \quad \mu_{y}=0
\end{aligned}
$$

The efficiency factor $\mu_{y}$ for lacings has a zero value, due to the negligible plastic reserve. Also, the contribution of $I_{\text {ch.y }}$ to the total $I_{\text {eff.y }}$ is negligible, due to the relatively large value of $h_{o . z}$. In the plane with battens, the bending stiffness is reduced depending on the member slenderness $\lambda: 0 \leq \mu_{z} \leq 1$. For $\lambda \leq 75$ the full $I_{c h, z}$ may be taken and $\mu_{z}=1.0$. For the very slender member with $\lambda \geq 150$ contribution of $I_{c h, z}$ to $I_{\text {eff }}$ is zero and $\mu_{z}=0$. The linear interpolation should be done between the slenderness 75 and 150 and $0<\mu_{z}<1.0$.

The shear stiffness $S_{v}$ for plane of the battens is determined according to 6.4.3.1 (EN 1993-1-1) as follows:

$$
S_{v . z}=\frac{24 E I_{c h, z}}{a_{r}^{2}\left[1+\frac{2 I_{c h, z}}{n_{b} I_{b}} \frac{h_{0, y}}{a_{r}}\right]}=5.03910^{4} \mathrm{kN} \leq S_{v, \max }=\frac{2 \pi^{2} E I_{c h, z}}{a_{r}{ }^{2}}=5.96210^{4} \mathrm{kN}
$$

where $n_{b}=4$ is the number of battened planes. $I_{b}$ is the second moment of area of a batten:

$$
I_{b}=\frac{1}{12}(200 m m)^{3} 4 m m=2.66710^{-6} \mathrm{~m}^{4}
$$

The shear stiffness $S_{v}$ is limited by the value $S_{v, \max }$, which takes into account the possible failure of a battened panel by shear.

The shear stiffness $S_{v}$ in the plane of the lacing is determined according to 6.4.2.1(4) Figure 6.9 [1] or 6.4.2.1(4) Figure 6.17 [2] as follows:

$$
S_{v \cdot y}=\frac{n E A_{d} a_{p} h_{0, z}}{2 d^{3}}=6.059510^{4} \mathrm{kN}
$$

where $n=1$ is the number of lacing planes and $d$ is the length of the diagonal:

$$
d=\sqrt{h_{o . z}^{2}+\left(\frac{a_{p r}}{2}\right)^{2}}=1.677 \mathrm{~m}
$$




\subsection{Calculation of internal forces on member with $S_{v}$ and $E_{\text {eff }}$}

The second order theory must be taken into account when calculating the internal forces in the built-up column. Exact values may be obtained using analytical formulae of Emeritus Professor Rubin from TU in Vienna [10], who derived formulae for 12 cases with different types of loads and boundary conditions. There are two important parameters influencing the calculation in these formulae. The member parameter $\varepsilon$, which takes into account the influence of the theory second order and the shear parameter $\gamma$, which takes into account the influence of shear deformations. Knowing $\varepsilon$ and $\gamma$ values the designer immediately knows the influence of the theory of the second order and the influence of the shear deformation without long calculation.

Table 1. The parameters $\gamma$ and $\varepsilon$.

\begin{tabular}{|c|c|}
\hline Parameters & Method of the calculation \\
\hline$\gamma=1$ & Without the influence of shear deformations \\
\hline$\gamma>1$ & With the influence of shear deformations \\
\hline$\varepsilon=0$ & Analysis of the $1^{\text {st }}$ order \\
\hline$\varepsilon>0$ & Analysis of the $2^{\text {nd }}$ order \\
\hline
\end{tabular}
a) $\gamma=\frac{1}{1-\frac{N_{E d}}{S_{v}}}$
b) $\varepsilon=L \sqrt{\frac{\gamma N_{E d}}{E I_{e f f}}}$

The external loading is located at the upper column free end, therefore $\xi_{M}=\xi_{H}=1$. The dimensionless coordinate $0 \leq \xi=\mathrm{x} / \mathrm{L} \leq 1$. The internal forces distributions may be obtained by using the following Rubin`s formulae:

The bending moment distribution due to horizontal force:

$$
M_{E d . H}(\xi)=\frac{\gamma \sin \left[\left(1-\xi_{H}\right) \varepsilon\right] \sin (\xi \varepsilon)}{\varepsilon \sin (\varepsilon)} L H_{E d}-\frac{\gamma \sin [(1-\xi) \varepsilon]}{\varepsilon \sin (\varepsilon)} \frac{\sin (\varepsilon) \sin \left[\left(1-\xi_{H}\right) \varepsilon\right]}{\varepsilon \cos (\varepsilon)} L H_{E d}
$$

The bending moment distribution due to external bending moment:

$$
M_{E d . M}(\xi)=-\left[\frac{\cos \left[\left(1-\xi_{M}\right) \varepsilon\right] \sin (\xi \varepsilon)}{\sin (\varepsilon)}+\frac{\sin [(1-\xi) \varepsilon]}{\sin (\varepsilon)} \frac{\cos \left[\left(1-\xi_{M}\right) \varepsilon\right]}{\cos (\varepsilon)}\right] M_{E d}
$$

The bending moment distribution due to the local bow initial imperfection with amplitude $e_{o}$ may be calculated as follows:

$$
M_{E d . e o}(\xi)=\frac{\gamma}{\varepsilon^{2}}\left[\frac{\cos [(0.5-\xi) \varepsilon]}{\sin (0.5 \varepsilon)}-1\right]\left(-8 N_{E d} e_{o}\right)
$$

The shear force distribution:

$$
V_{E d}(\xi)=\left(\frac{d M_{E d}(\xi)}{d(\xi)}\right) / L
$$


Table 2 shows the important values for both buckling planes. The effect of shear deformation is negligible in both planes $x z$ - and $x y$-planes $(\gamma=1.017$ and $1.02 \approx 1.0)$. The influence of the second order theory is in the $x z$-plane negligible $\left(\varepsilon_{y}=0.221 \approx 0\right)$ and in the $x y$-plane it has a big influence $\left(\varepsilon_{z}=1.383>0\right)$. The influence of the second order theory may be seen from the values of parameter $\alpha_{\mathrm{cr}}$ too. The values of the elastic critical forces used for calculation of parameter $\alpha_{\mathrm{cr}}$ are as follows:

$$
\begin{aligned}
& N_{c r . y}=\frac{\pi^{2} E I_{\text {eff.y }}}{L_{c r . y}^{2}}=51210 \mathrm{kN} ; \quad L_{c r . y}=2 L=16.5 \mathrm{~m} \\
& N_{c r . z}=\frac{\pi^{2} E I_{\text {eff } . z}}{L_{c r . z}^{2}}=5264 \mathrm{kN} ; \quad L_{c r . z}=L=8.25 \mathrm{~m}
\end{aligned}
$$

The elastic critical forces taking into account the shear deformation:

$$
\begin{aligned}
& N_{c r . y \cdot v}=\frac{1}{\frac{1}{N_{c r . y}}+\frac{1}{S_{v \cdot y}}}=27750 \mathrm{kN} ; \\
& N_{c r . z . v}=\frac{1}{\frac{1}{N_{c r . z}}+\frac{1}{S_{v \cdot z}}}=4766 \mathrm{kN} ;
\end{aligned}
$$

Table 2. The values of the parameters $\gamma, \varepsilon, \mathrm{N}_{\mathrm{cr}}, \mathrm{N}_{\mathrm{cr}, \mathrm{v}}, \alpha_{\mathrm{cr}}$ for both buckling planes.

\begin{tabular}{|c|c|c|}
\hline Phenomenons and parameters & $\begin{array}{c}\text { In the } \boldsymbol{x z} \text {-plane with } \\
\text { lacings (i) }\end{array}$ & $\begin{array}{c}\text { In the } \boldsymbol{x} \boldsymbol{y} \text {-plane with } \\
\text { battens (ii) }\end{array}$ \\
\hline The influence of shear deformations & $\gamma_{\mathrm{y}}=1.017$ & $\gamma_{\mathrm{z}}=1.02$ \\
\hline Analysis of the $2^{\text {nd }}$ order & $\varepsilon_{\mathrm{y}}=0.221$ & $\varepsilon_{z}=1.383$ \\
\hline The elastic critical buckling load & $\mathrm{N}_{\text {cr.y }}=51210 \mathrm{kN}$ & $\mathrm{N}_{\text {cr. } \mathrm{z}}=5264 \mathrm{kN}$ \\
\hline $\begin{array}{c}\text { Critical force with the influence of shear } \\
\text { deformations }\end{array}$ & $\mathrm{N}_{\text {cr.y.v }}=27750 \mathrm{kN}$ & $\mathrm{N}_{\text {cr.z.v }}=4766 \mathrm{kN}$ \\
\hline The parameter $\alpha_{\text {cr }}=\mathrm{N}_{\text {cr.v }} / \mathrm{N}_{\mathrm{Ed}}$ & $\alpha_{\text {cr.y }}=27.75>10$ & $\alpha_{\text {cr. }}=4.77<10$ \\
\hline
\end{tabular}

\section{Numerical solution}

Two models were created for numerical solution. Simplified frame model (A) and discrete model (B). The simplified model was solved by two independent programs ANSYS (A1 results) and IQ100 (A2 results). The discrete model (B results) was created in ANSYS.

\subsection{Simplified frame model (A)}

The geometry of the simplified model and the load are shown in Figure 2. The boundary conditions in the $x z$ plane $(\perp y)$ : the bottom member end is fixed and the upper end is free. The joints of the diagonals with the chords are modeled as hinges. The boundary conditions 
in the $x y$ plane $(\perp z)$ : the both member ends are simply supported. The joints of the diagonals with the chords are modeled as hinges. The individual chords are loaded by forces calculated from the load shown in Figure 1. The cross-section properties of the chord consisting from $2 \mathrm{x} \mathrm{C}$-sections are as follows:

$$
\begin{gathered}
A=2 A_{c h}=5.97910^{-3} \mathrm{~m}^{2} \\
I_{e f f, z}=2\left[\mu_{z} I_{c h, z}+A_{c h}\left(\frac{h_{0, y}}{2}\right)^{2}\right]=8.64410^{-5} \mathrm{~m}^{4} ; \quad I_{y}=2 I_{c h . y}=2.8610^{-5} \mathrm{~m}^{4}
\end{gathered}
$$

The cross-section properties of the diagonal:

$$
\begin{gathered}
A_{p}=8.06510^{-4} \mathrm{~m}^{4} \\
I_{y \cdot p}=1.3510^{-6} \mathrm{~m}^{4} ; \quad I_{z \cdot p}=6.3910^{-7} \mathrm{~m}^{4} ; I_{T \cdot p}=2.5210^{-9} \mathrm{~m}^{4} ; I_{\omega . p}=1.4210^{-9} \mathrm{~m}^{6}
\end{gathered}
$$
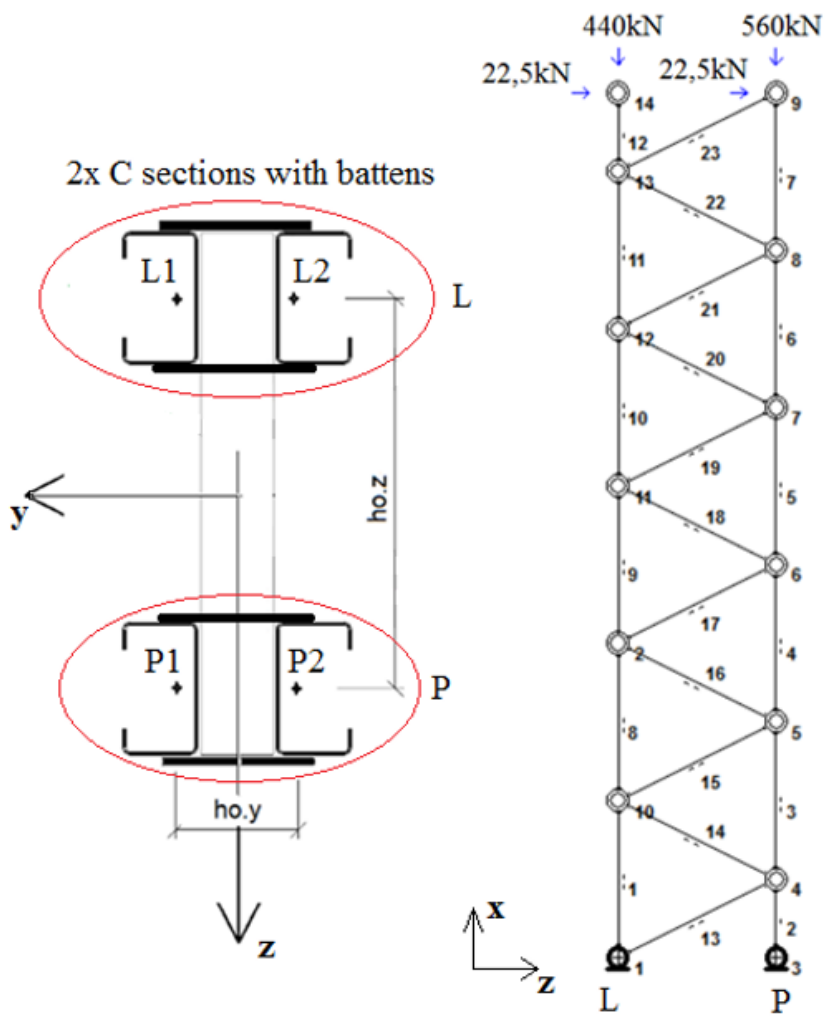

Fig. 2. Simplified frame model A. Statical scheme used by IQ 100.

The results of all calculations in the critical section $x=0$ are shown in Table 3 .

(A1 results) The simplified model A in ANSYS [11] is created using BEAM188 elements. This element is based on Timoshenko`s beam theory. Shear deformation effects are included. An ASEC subtype is used that allows to specify any cross-section by defining its cross-section properties. 
Both linear and nonlinear analyses were performed. Geometrical nonlinear analysis took into account the large deformations.

(A2 results) The program IQ 100 was developed by prof. H. Rubin, M. Aminbaghai and $\mathrm{H}$. Weier at the TU in Vienna [12]. The linear analysis of the $1^{\text {st }}$ order with the influence of shear deformations and the nonlinear analysis of the $2^{\text {nd }}$ order with the influence of shear deformations were performed with IQ 100.

\subsection{Discrete model (B)}

The discrete model in ANSYS consists of SHELL181 elements. The connections of the battens and lacings with the chords are rigid. The boundary conditions are the same as in paragraph 3.1 The load is the same as in model A. The analyzes are performed as in the calculation A1.

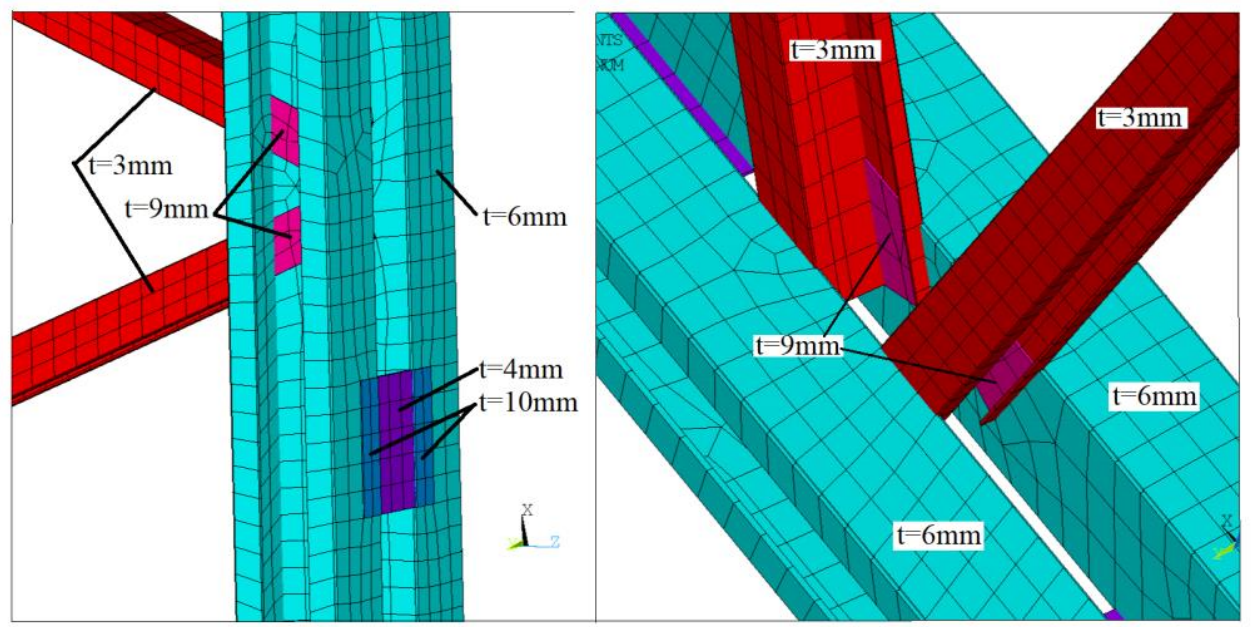

Fig. 3. Details of the connection of chords with battens and lacings (ANSYS).

\section{The comparison of the results of numerical and analytical solutions}

The results of the solution were obtained for one C-section of the built-up column in the critical section $x=0$ as follows: (i) linear $1^{\text {st }}$ order analysis, (ii) nonlinear $2^{\text {nd }}$ order analysis taking into account large deformations in ANSYS calculation (Table 3). The $\mathrm{B}$ results are obtained from the average value of the stresses in the nodes, at the fixed end of the chord. The normal force in C-section in the analytical solution can be obtained from the formula (6.69) given in 6.4.1(6) in EN 1993-1-1 [1] or from the formula (6.72) given in 6.4.1(6) in EN 1999-1-1 [2]:

$$
N_{c h, E d}=\frac{N_{E d}}{4} \pm \frac{M_{E d}(x) h_{o} A_{c h}}{2 I_{e f f}}
$$

Table 3 shows the normal force values in the most stressed section $x=0$. The chord cross-section is shown in Figure 2 together with the numbering of the left $(\mathrm{L})$ and the right (P) members $\left(\mathrm{L}_{1} ; \mathrm{L}_{2} ; \mathrm{P}_{1} ; \mathrm{P}_{2}\right)$. 
Table 3. The comparison of the normal forces $\mathrm{N}_{\mathrm{ch}, \mathrm{Ed}}(\mathrm{x}=0)$ values of various analyses.

\begin{tabular}{|c|c|c|c|}
\hline Model & $\begin{array}{c}\text { Nch,Ed in } \\
\text { 1xC- } \\
\text { section }\end{array}$ & $\begin{array}{c}\text { Linear } \\
\text { analysis } \\
\text { with shear } \\
{[\mathbf{k N}]}\end{array}$ & $\begin{array}{c}\text { Nonlinear } \\
\text { analysis } \\
\text { with shear } \\
\text { [kN] }\end{array}$ \\
\hline $\begin{array}{c}\text { Analytical } \\
\text { solution }\end{array}$ & $\mathbf{N}_{\text {ch.Ed.L1,2 }}$ & -94.18 & -91.33 \\
& $\mathbf{N}_{\text {ch.Ed.P1,2 }}$ & -405.83 & -408.64 \\
\hline $\begin{array}{c}\text { A1 results } \\
\text { (ANSYS) }\end{array}$ & $\mathbf{N}_{\text {ch.Ed.L1,2 }}$ & -98.53 & -84.77 \\
\hline A2 results & $\mathbf{N}_{\text {ch.Ed.P1,2 }}$ & -401.47 & -415.23 \\
(IQ100) & $\mathbf{N}_{\text {ch.Ed.P1,2 }}$ & -102.92 & -97.88 \\
\hline & $\mathbf{N}_{\text {ch.Ed.L1 }}$ & -108.49 & -104.55 \\
B results & $\mathbf{N}_{\text {ch.Ed.L2 }}$ & -106.63 & -102.60 \\
(ANSYS) & $\mathbf{N}_{\text {ch.Ed.P1 }}$ & -389.39 & -394.69 \\
& $\mathbf{N}_{\text {ch.Ed.P2 }}$ & -389.71 & -395.48 \\
\hline
\end{tabular}

\section{Conclusion}

The procedure given in EN 1993-1-1 [1] and EN 1999-1-1 [2] is limited to the very simply cases. The calculations in this paper show how to design much more complex structures under general type of loading. The paper deals with extremely complex case: the two-chords single laced column with four parallel battened planes. The column cross-section consists from four C-sections made of cold formed steel. Lacing is made from C-profiles too. Both analytical and numerical solutions are presented and their results are compared. The comparison of the results in Table 3 shows acceptable agreement of internal forces in chords of built-up column in the critical section $x=0$. The values of the important parameters $\gamma, \varepsilon, \alpha_{c r}$ (Table 2) are very important output of the analytical solution. These parameters give to the designer very useful information about built-up members without doing consequent large calculations. For example the first order analysis may be used for the structure if $\alpha_{c r} \geq 10$ (15) in elastic (plastic) analysis. Concerning investigated column it may be stated: (i) the effect of shear deformation is negligible in both planes $x z$ - and $x y$-plane $(\gamma=1.017$ and $1.02 \approx 1.0)$, (ii) in the $x z$-plane there is negligible influence of the second order theory $\left(\varepsilon_{y}=0.221 \approx 0\right)$ and in the $x y$-plane it has a big influence $\left(\varepsilon_{z}=1.383>0\right)$. The values of these parameters important for designers may be easily obtained from formulae (14).

Project No. 1/0603/17 and 1/0244/20 are supported by the Slovak Grant Agency VEGA.

\section{References}

1. EN 1993-1-1:2005 and Corrigendum AC (2006) and Corrigendum AC (2009) and Amendment A1 (2014). Eurocode 3: Design of steel structures. Part 1.1: General rules and rules for buildings. CEN Brussels

2. EN 1999-1-1:2007 and Amendment A1 (2009) and Amendment A2 (2013). Eurocode 9: Design of aluminium structures.Part 1.1: General structural rules. CEN Brussels 
3. I. Baláž, Y. Koleková, L. Moroczová, ESaT 2018. Košice, (2018)

4. I. Baláž, Y. Koleková, L. Moroczová, ESaT 2018. Košice, (2018)

5. I. Baláž, Y. Koleková, L. Moroczová, Book of extended abstracts of 34th conference with international participation Computational Mechanics 2018. (2018)

6. I. Baláž, Y. Koleková, L. Moroczová, Zborník prednášok zo 43. aktívu pracovníkov odboru ocel'ových konštrukcií. (2018), (in Slovak)

7. I. Baláž, Y. Koleková, L. Moroczová, Advances and Trends in Engineering Sciences and Technologies III. London: Taylor \& Francis Group, (2019)

8. I. Baláž, Y. Koleková, L. Moroczová, Advances and Trends in Engineering Sciences and Technologies III. London: CRC PressTaylor \& Francis Group, (2019)

9. I. Baláž, Y. Koleková, L. Moroczová, KYSEL, J. Statika stavieb 2019. Trnava: Spolok statikov Slovenska, (2019), (in Slovak)

10. Stahlbau Handbuch fur Studium und Praxis. Band 1, Stahlbau-Verlag, (1982)

11. ANSYS Academic Research, Release 19.0, Help System. ANSYS, Inc. (2018)

12. H. Rubin, M. Aminbaghai, H.Weier, IQ100, Vollversion, Feb.2010,TU Wien, (2010) 